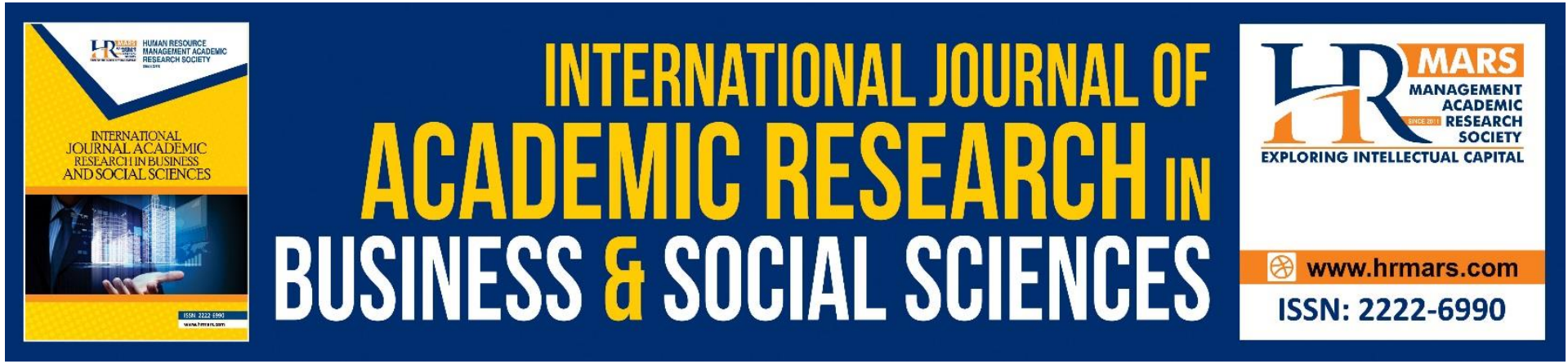

\title{
Nurses' Perception of Structural Empowerment in Commitment Towards Quality Improvement Sustainability
}

Elaine Heng, Beni Widarman Yus Kelana, Saiful Azizi Ismail, Sanil S Hishan

To Link this Article: http://dx.doi.org/10.6007/IJARBSS/v11-i8/10682

DOI:10.6007/IJARBSS/v11-i8/10682

Received: 06 June 2021, Revised: 29 June 2021, Accepted: 17 July 2021

Published Online: 07 August 2021

In-Text Citation: (Heng et al., 2021)

To Cite this Article: Heng, E., Kelana, B. W. Y., Ismail, S. A., \& Hishan, S. S. (2021). Nurses' Perception of Structural Empowerment in Commitment Towards Quality Improvement Sustainability. International Journal of Academic Research in Business and Social Sciences, 11(8), 113-124.

Copyright: (c) 2021 The Author(s)

Published by Human Resource Management Academic Research Society (www.hrmars.com)

This article is published under the Creative Commons Attribution (CC BY 4.0) license. Anyone may reproduce, distribute, translate and create derivative works of this article (for both commercial and non-commercial purposes), subject to full attribution to the original publication and authors. The full terms of this license may be seen at: http://creativecommons.org/licences/by/4.0/legalcode

Vol. 11, No. 8, 2021, Pg. 113 - 124

http://hrmars.com/index.php/pages/detail/IJARBSS

JOURNAL HOMEPAGE

Full Terms \& Conditions of access and use can be found at http://hrmars.com/index.php/pages/detail/publication-ethics 


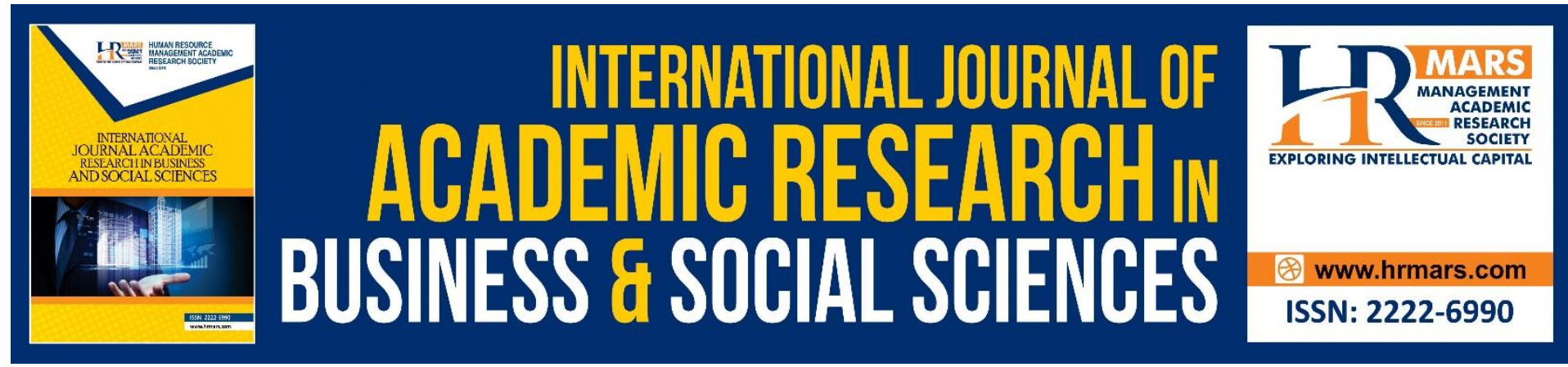

\title{
Nurses' Perception of Structural Empowerment in Commitment Towards Quality Improvement Sustainability
}

\author{
Elaine Heng ${ }^{\mathrm{a}}$, Beni Widarman Yus Kelana ${ }^{\mathrm{b}}$, Saiful Azizi \\ Ismail $^{c}$, Sanil S Hishan ${ }^{d}$ \\ ${ }^{1}$ Azman Hashim International Business School, Universiti Teknologi Malaysia, 81100, Johor \\ Bahru, Malaysiaa, ${ }^{2}$ Azman Hashim International Business School, Universiti Teknologi \\ Malaysia, 54100, Kuala Lumpur, Malaysia ${ }^{b},{ }^{3}$ School of Business Management, Universiti \\ Utara Malaysia, 06010 Sintok, Malaysia c , ${ }^{4}$ Azman Hashim International Business School, \\ Universiti Teknologi Malaysia, 81100, Johor Bahru, Malaysia ${ }^{d}$ \\ Email: henggg78@gmail.com ${ }^{a}$, beni@utm.my ${ }^{b}$, saifulazizi@uum.edu.comc, \\ sshishan@utm.my ${ }^{d}$
}

\begin{abstract}
The purpose of this study is to examine the level of nurses' perception on key predictors of structural empowerment that provided at workplace, which could influence the nurses' commitment towards sustainability activities through QI in healthcare, Malaysia. The researcher has utilized the dominant elements of the Quality Improvement Framework (2016) developed by National Improvement (QI) team and relate to the conceptual links of Kanter's Structural Theory of Power in Organizations $(1977,1993)$ to form the conceptual framework to support the current basic quantitative study. A total of 315 nurses from 5 private specialist hospitals in Johor, Malaysia was participated in the current study. Data were analyzed using descriptive statistics and structural equation modelling (SEM) analyses. Through descriptive statistics, results revealed that the nurses perceived themselves to empower with moderate to high level of powers gains through their existing formal and informal QI activities/system, as well as accesses to job-related empowerment structures in the workplace that could enhanced their commitment towards QI sustainability. SEM analysis indicated that a significant effect of job-related empowerment structures and the nurses' commitment towards sustainable QI practices in local private healthcare sector in Johor, Malaysia. In conclusion, nurses can be empowered for sustainability activities through QI at all levels in the healthcare organization if they are empowering with sufficient and efficient of fundamental keys of job-related empowerment structures in workplace.
\end{abstract}

Keywords: Structural Empowerment, Quality Improvement, Sustainability, Continuous Professional Education \& Training, Resources Adequacy, Shared Governance, Transformational Leaderships, Professional Teaching \& Role Development, Interdisciplinary Collaboration. 


\section{Introduction}

Continuous quality improvement (QI) is pervasive in current contemporary healthcare. Efforts to improve patients' safety, quality care and services in provision often focused on changing / updating to the latest evidence-based practices. Previous researches shown it could successfully implement in some healthcare organizations while failing or stagnating in others, and working environments and practice settings were shown remained fraught with barriers/challenges, includes resistance from healthcare providers as a QI initiative/project is launched, during implementation and execution. Nurses often perceived QI work/change could be a threat to their clinical practices, identity, power and status (Van Oostveen \& Vermeulen, 2017). hanges could be challenging as it contradicts with the essential needs of humans for a stable environment (Nilsen et al., 2020). The author suggests that the easiest and rarely encountered resistance to organizational changes in healthcare when health care practitioners have the opportunity to influence, understand the importance value and feel ready for the change for improving. To simply it, leaked of the management perspective to align the key organization needs and processes, and employees' needs will lead to unsuccessful changes (Nilsen et al., 2020). However, with the importance of commitment as the driver towards QI sustainability, there is a leaking of research draws on the nurses' perception of supports or access to healthcare organizational structures for realizing sustainable QI outcomes, which overall may influence the nurses' execution or managerial behaviors and attitudes in response towards sustainability activities / initiatives through their mandate QI. Supported by Doyle (2013), who highlights that factors contributing to the sustainability of improvement initiatives often relate to the planning and implementation of the improvement initiative from the outset. The author suggests should have an interdependent relationship between factors influencing initial success and those influencing long-term success and sustainability in QI. A review conducted by Doyle (2013), on the Innovation and Improvement Sustainability Model from National Health Service (NHS) Institute, and it justified as to increase awareness from its 10 most valuable of sustainability determinants that had facilitated the knowledge translation in a checklist format. Even though the evidence suggested for an overlap of factors influencing both implementation progress and sustainability, but there was still no clarification related to what conditions may enhance in initial success, which subsequently helps in QI sustainability, especially is importance to influence the engagement of nurses in QI execution especially during their busy / chaotic and complex daily works. In other words, an initiative can achieve initial success by providing extra resources or putting pressure on the workforce, but the benefits will not be sustained once the resource or pressure is removed in their local context. Thus, this study will be emphasized that the nurses can be empowered for sustainability activities through QI at all levels in the healthcare organization if they are empowered with necessary fundamental key supports of job-related empowerment structures at workplace, especially in healthcare, Malaysia.

"LINKING PIN" BETWEEN STRUCTURAL EMPOWERMENT AND COMMITMENT TOWARDS QI SUSTAINABILITY 
Table 1 presents a brief explanation of past studies showing the relationship between structural empowerment and commitment towards QI sustainability to strengthen the evidence conceptually:

TABLE 1. Relationship between structural empowerment and commitment towards QI sustainability

\begin{tabular}{|c|c|}
\hline $\begin{array}{c}\text { Structural } \\
\text { Empowerment }\end{array}$ & Remarks \\
\hline $\begin{array}{c}\text { Continuing } \\
\text { Professional } \\
\text { Education \& } \\
\text { Training }\end{array}$ & $\begin{array}{l}\text { Access to opportunity refers to the opportunity to enhance knowledge and } \\
\text { skills and the possibility for growth and movement within the organization } \\
\text { (Kanter,1993). Practically, parts of the roles and responsibilities of } \\
\text { professional nurses in quality improvement (QI) includes conducting } \\
\text { interdisciplinary processes to achieve organizational QI goals by measuring, } \\
\text { improving and controlling with the use of QI standard protocol / algorithms / } \\
\text { flowchart, etc. Even though those standardization helps to ensure that all QI } \\
\text { methods or processes are carry out consistently over time in a healthcare } \\
\text { organization, but nurses still need to utilize their own professional knowledge } \\
\text { and clinical judgment in order to achieve a quality care agreement. Therefore, } \\
\text { continuing professional education and training are important to keep nurses } \\
\text { up-to-date on the latest advances in care and treatment, which involves } \\
\text { formal education, informal education through on-job learning/training, } \\
\text { professional certification, conferences, etc. As supported by Aiken (2014), and } \\
\text { findings revealed that higher proportions of nurses as baccalaureate degree } \\
\text { holders had significant relationships with lower failure rate to rescue and } \\
\text { mortality rate in surgical patient. However, a research conducted by Ebrahimi } \\
\text { (2012), result indicated that barriers for nurses in acquiring continuous } \\
\text { education were enormous expenditures, staff shortage, unaware of the } \\
\text { course scheduling, time consumption and lack of managers' support. } \\
\text { Therefore, the nurse managers/leaders should prioritize the nurses' learning } \\
\text { needs to educate, train and equip with a relevant and appropriate knowledge } \\
\text { and skills/competencies, which predict will influence the nurses' behaviors } \\
\text { change in their commitment towards sustainability activities through QI. }\end{array}$ \\
\hline $\begin{array}{l}\text { Resources } \\
\text { Adequacy }\end{array}$ & $\begin{array}{l}\text { Access to resources refers to an ability of a person to acquire the financial } \\
\text { includes supplies, materials and times that required for the works to be done } \\
\text { (Kanter,1993). Abbasi (2013), stated that healthcare systems all around the } \\
\text { world are being pushed by two opposing forces: the need to meet rising } \\
\text { demand and the desire to reduce healthcare costs. The author claimed that a } \\
\text { nursing team that running around in a hassle and chaotic environment would } \\
\text { cause trouble focusing on standard QI activities, includes affected performance } \\
\text { in providing best patient care and services when the nurses are burned out, } \\
\text { morale is low, and their opinions and concerns are regularly ignored in relation } \\
\text { to works overloaded. Thus, suggested that nurse managers must include } \\
\text { effective budget practices and a sufficient staffing schedule which will be a } \\
\text { promising in engagement and QI activities (Abbasi,2013). Supported by Frich et }\end{array}$ \\
\hline
\end{tabular}


al. (2015), research results revealed that the creation of good capable nurse leaders/managers to be involve in the execution of leadership/

management development programs intended to enhance healthcare workforce capacity and quality, reducing turnover and its associated costs and prioritizes the focus on strategies particularly related to the effectiveness and efficiency of the service delivery of sustainable patient quality care and safety. Thus, if allows the nurses or nurse managers/leaders to have their own autonomy and resources to initiate, manage, and ultimately self-determination on their own work processes and creative improvement ideas which may have a significant impact to motivate their commitment in QI sustainability (Kanter,1993). A study supported by Morrell \& Daniel (2011), and results highlighted that by given the budget limitations in many health facilities, nonmonetary benefits or rewards can help to boost employee commitment and motivate them in certain behaviors intrinsically.

Access to Information refers to necessary formal and informal knowledge and skills that needed to get the job done, includes an understanding of organizational policies and decisions (Kanter,1993). Supported by Islam (2014), and the results emphasized that it is more practical to empower the front-line nurses in a shared vision of unit ownership rather than an employeeemployer relationship built in hierarchical and authoritarian styles. Proposed this type of shared governance to empower nurses to exert control over the health care environment, by participation and feedback reinforces the investment of the nurses in their quality decisions and ensures that nurses understand the implications of any QI initiative or program on their clinical Share work-flows (Islam,2014). Shared governance pioneer Porter (2001), defines Governance shared governance as "shared governance as "a structural model whereby nurses can communicate and manage their practices with a higher degree of professional autonomy." It is important to know the nurses ' viewpoint / perspectives and experiences, then utilize it as information relates to the service deliveries, and prioritize the nurses' personal goals and performance as well, not just putting all account-abilities of QI processes to QI councils / committees. Nurses as active partners in decision-making within the organization and their voices should be respected and valued for their expertise and outstanding patient care. Therefore, it is critical to build a culture of shared governance to increase their autonomy in QI decision making which is essential to influence their behaviors towards sustainability activities through QI.

\section{Transformatio nal Leaderships}

Access to support implies to receive feedback and guidance from superiors, subordinates, and peers (Kanter,1993). Therefore, it is crucial for the nurse managers/leaders need to utilize their idealized influence Marshall (2011), in building commitment to achieve the vision set, align nurses toward the goals and provide inspiration, motivation for the nurses to get involved, and allow nurses to spend time in creating, monitoring, and enhancing care processes. Abdallah (2014), reveals that internal factors connected between leadership and personnel played a significant effect on the failure or success 


\begin{tabular}{|c|c|}
\hline & $\begin{array}{l}\text { of a quality initiative. The author suggested that in order to guarantee a } \\
\text { positive outcome and identify the potential obstacles or efficient drivers, the } \\
\text { nurse managers must adopt a structured implementation strategy that can } \\
\text { provide an efficient process of decision making in any QI works. For example, } \\
\text { nurse managers / leaders play a crucial role in intellectual stimulation and } \\
\text { individual consideration Marshall (2011), by giving transparency and clear } \\
\text { through routine meeting/communication as well as offering support for a } \\
\text { "can do" culture values to motivate nurses' positive change in engaging } \\
\text { themselves in Ql activities. Supported by Andreasson, Eriksson \& Dellve, } \\
\text { (2016), the research revealed that trustful relationships could be fostered } \\
\text { through regular interaction between managers and employees, which is } \\
\text { important for achieving higher employees' commitment towards } \\
\text { organizational change. A similar study conducted by Rajasekhar (2016), and } \\
\text { reported that feedback sessions improved engagement in QI, meanwhile } \\
\text { proven the main challenge includes difficulty organizing meetings set-up, as } \\
\text { well as engaging certain specialty groups in healthcare. In the face of limited } \\
\text { resources and fast change in the health-care facilities, non-monetary } \\
\text { benefits or rewards could help to boost employee commitment and motivate } \\
\text { them in certain behaviors intrinsically (Morrell \& Daniel, 2011). Agreed by } \\
\text { Homer et al. (2014), that in order to achieve an organizational change, it } \\
\text { requires a committed, competent, and passionate transformative leadership } \\
\text { to establish and articulate a vision, developing the necessary relationships, } \\
\text { allocating and prioritizing resources to facilitate the change. As supported by } \\
\text { Abbasi ( } 2013 \text { ), result suggested that nurse managers must include effective } \\
\text { budgeting practices and a sufficient staffing schedule which will be a } \\
\text { promising in engagement and Ql activities. Thus, all nurse managers should } \\
\text { connect with their teams on a regular basis to understand the nurses' needs, } \\
\text { so that the nurses can be equipped with the appropriate structures/tools to } \\
\text { further motivate nurses to be productive and enhance their commitment } \\
\text { towards Ql sustainability. }\end{array}$ \\
\hline $\begin{array}{c}\text { Teaching \& Role } \\
\text { Development }\end{array}$ & $\begin{array}{l}\text { An access to opportunity structures and access to power structures } \\
\text { (resource, information and support) could be enhanced by formal power, } \\
\text { which derived from a characteristic of a specific job: flexibility, creativity, and } \\
\text { adaptability, which corrected to discretionary decision-making, visibility, and } \\
\text { centrality to the organization's objectives and goals (Kanter,1993). In today's } \\
\text { QI efforts, healthcare organizations often utilize on board or orientation } \\
\text { programs for newly recruited nurses, as a chance to show the commitment } \\
\text { of their organization towards organizational learning and addressing the } \\
\text { healthcare organization's culture in commitment towards QI sustainability at } \\
\text { the entry point. Each healthcare organization has its own justification for } \\
\text { mentorship or preceptorship which facilitates best clinical practices and } \\
\text { professional growth for mentor / preceptor. According to Lewis \& McGowan } \\
\text { (2015), and reported that presenting takes extra time and energy, which that } \\
\text { has often described as stressful and burdensome for nurses who may already } \\
\text { feel overwhelmed with their routine workloads. In addition, a preceptor } \\
\text { must be introduced about their new job and responsibilities once he/she }\end{array}$ \\
\hline
\end{tabular}


have been chosen. Therefore, to keep preceptors relevant, formalized training on preceptor education is necessary. In other words, those chosen nurses can be demotivated due to lack of formal training in preceptorship or mentorship orientation program and ongoing opportunities to further their clinical advancement. As supported by Trede, Sutton, \& Bernoth (2015), the research revealed that preparing the position of a preceptor needs to be cautious to ensure its effectiveness, including a clear definition of the role, goals, instructional philosophies, and the skill of providing and receiving evaluative feedback. Insufficient clarity and recognition of the role in the workplace can lead to misconceptions about what preceptors are and what they might anticipate (Trede, Sutton, \& Bernoth, 2015). Besides that, recognition of achievement and their participation in preceptorship/mentorship, and awards provided as symbolized status (power) with an acknowledgement title or rewarding with an increment in incentive can definitely drive motivation and participation (Martensson et al., 2012). If nurses can feel or see that their recognition / acknowledgement is corresponding with their contribution efforts, then they are more likely to develop their confidence, abilities and capacity to work, indeed experience greater power and a sense of empowerment in the workplace.

Another access to opportunity structures and access to power structures (resource, information and support) could enhance by informal power, which derived from communication \& information channels and social connection development, involved subordinates, peers, sponsors, and multi-functional groups (Kanter,1993). Problem-solving and decision-making are essential Interdisciplinary aspects of daily complex practices of physicians / consultants, nurses and allied Collaboration healthcare personnel. Supported by Reader (2017), and research results emphasized that team decision-making in a hospital setting is critical, and often marked by time pressures and rapidly changing environments. Thus, the author suggested both doctors and nurses must exchange information details, and the team leader incorporates all the information/data and makes a final judgement. The recommendations from the Institute of Medicine (2015), include strengthening the evidence base inter-professional education by connecting to modifications of collaborative behaviors. The experts suggested for simulation types of Event Based Approach to Training not only to offer opportunity for "hands-on" practice and enables teamwork concept to be integrated into knowledge and skill training, as well as provide a strong solution for sharing competencies and information interdisciplinary in a cooperative and clearer perception in the work environment. However, there are structural obstacles that often prevent collaboration and effective communication in the healthcare environment. Particularly, those simulation training consumed significant investment of financial resources, times and efforts/energy to build an effective teamwork system for developing a more coordinated healthcare delivery system. Supported by Légaré et al., (2011), a scarcity of resources and a power imbalance among health providers. On the other hand, the results supported that Professional education and training, as well as incentive for collaborative decision-making and mutual awareness of interdisciplinary 
responsibilities, were critical facilitators to succeed the team effectiveness. Hence, can conclude that the crucial elements of team effectiveness through effective interdisciplinary collaboration and communication training/structures, and creative motivational tools provided to encourage the nurses' participation in shared team decision making, transfer / exchange of information and changes, which predict in enhancing nurses' commitment towards sustainable QI practices.

\section{Method}

Data were analyzed using descriptive statistics and structural equation modelling (SEM) analyses. SEM is a statistical technique that is able to simulate and produce the results of the relationship between several contracts consisting of dependent and independent variables (Hair et al., 2014). The data collection was utilized quantitative methods prioritized validity and reliability. The questionnaires were distributed through an online survey. Simple random sampling was used to provide all the 5 clusters equal chances of being selected and it helps the researcher to interpret sample findings using statistical methods. A total of 315 nurses from 5 private specialist hospitals in Johor, Malaysia were participated in the current study.

\section{Result and Discussion}

This research analysis has been carried out based on the data collection, in order to meet the objectives of the current research. A descriptive analysis using SPSS 23 application for: 1) total 4 demographic analysis; 2 ) the objective 1 which to examine the nurses' perception on the 6 key predictors of job-related empowerment structures that provided in the workplace that suggest would influence the nurses' commitment towards QI sustainability by using score min value. The results of the analysis shown high to moderate average mean score, which includes that the nurses perceived themselves to have the highest level of empowerment through Shared Governance; whereby the lowest level of empowerment via Continuing Professional Education \& Training. Next, SEM analysis has been utilized to answer for the objective 2, to identify the significant effect between structural empowerment and commitment towards QI sustainability. The analysis shown that total 6 key predictors of job-related empowerment structures as independent variables have significant effects on the dependent variable (Commitment towards QI Sustainability) as (hypothesis accepted at $P \leq 0.05$ ). Meanwhile, the total value of the variance contributed by the 6 factors to the commitment towards QI sustainability was 0.429 (42.9 percent) while the other 57.1 percent was influenced by other additional factors that has yet to be identified. 


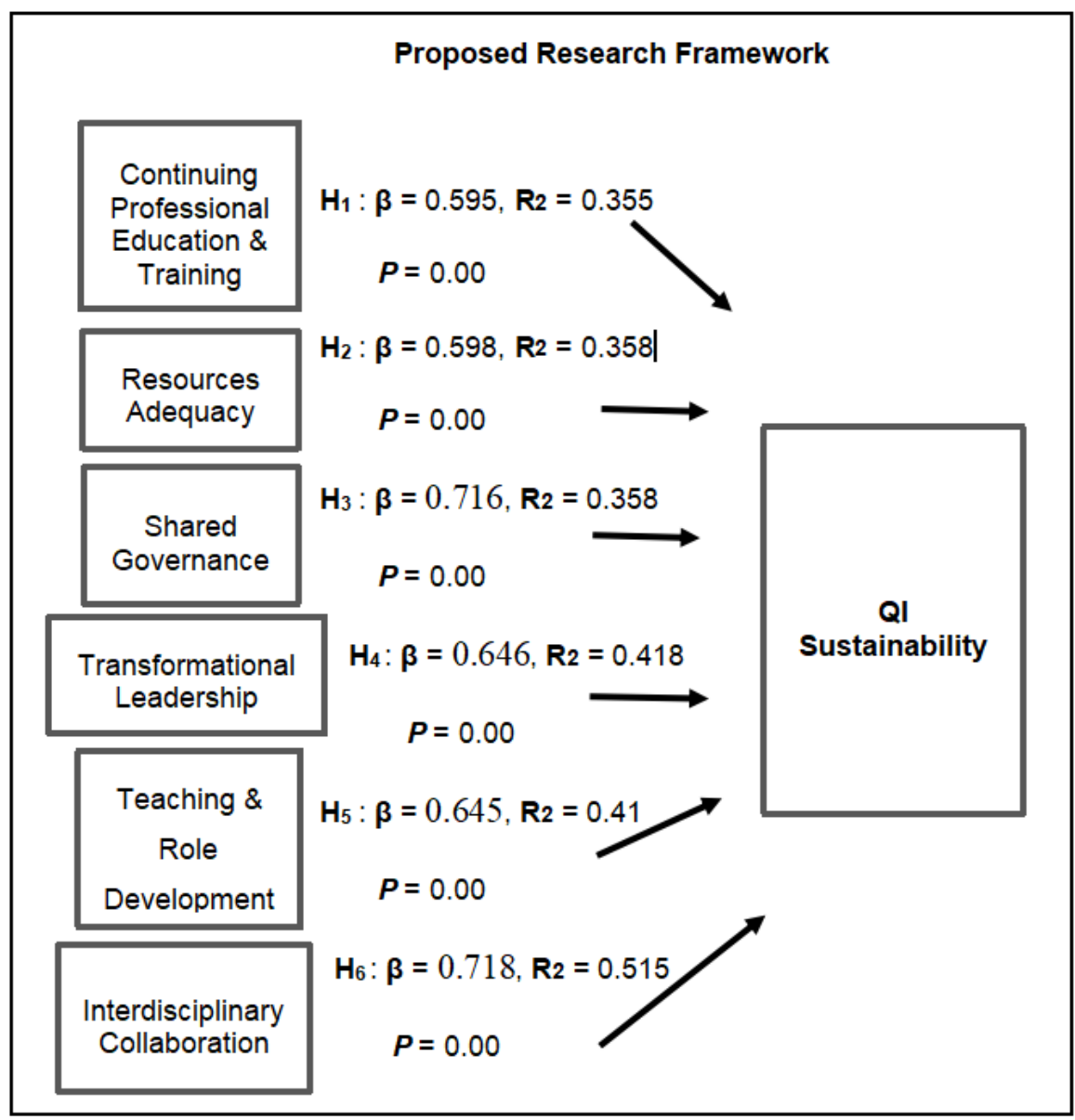

FIGURE 1. Result of SEM analysis (Significant effects of structural empowerment and commitment towards QI sustainability).

\section{Conclusion}

The current study results indirectly revealed that nurses were working in moderate to high level of empowered workplace that influenced their professional behaviors in committing towards sustainability activities through QI in local health care context. In conclusion, nurses can be empowered for sustainability activities through $\mathrm{Q}$ l at all levels in the healthcare organization if they are empowered with sufficient and efficient of the fundamental keys of job-related empowerment structures in the workplace. The researcher has recommended for the future researcher to explore more aspects on new key factors of job-related empowerment structures at the workplace in greater depth in order to understand better for health care teams' attitude, behavioral, cultural, and values factors that influence their commitment towards sustainability activities through QI.

\section{Contribution}

The researcher tried to relate the well-defined Quality Improvement Framework developed by Quality Improvement Division (2018), in the more general QI conceptual framework which has promote a person-centeredness culture that promotes and supports continuous quality improvement to the conceptual links of Kanter's Structural Theory of Power in Organizations for its proposition dimensions of formal and informal powers that suggests would influences the access to opportunity structures and another total 3 power structures (access to 
resources, support and information) (Kanter,1993). The researcher had proposed a new model framework with 6 identified empowerment structures based of Kanter's proposition dimensions which predict by empowering the best structural needs / supports for nurses that could influence their commitment towards sustainability activities through QI. The current study results have proven the significant effect of structural empowerment workplace and commitment towards QI sustainability. Again, proven that the Kanter's Structural Theory of Power in Organizations who emphasized that the employees' work behavior is influenced by the conditions and situations in the workplace (Kanter,1993). This theoretical contribution is helpful to emphasize in the literature, especially in the current Malaysia healthcare systems, and mostly throughout the globe that have desires to proceed with cost-effective but sustainable healthcare systems.

The practical implication of the results not only enables nurses to self-assess against 6 new key predictors of job-related empowerment structures that could empower their commitment towards sustainability activities through QI in their local healthcare context. Secondly, the empirical findings of the study will assist the nursing management / policy makers in understanding the importance to enhance nurses' commitment, as key driver towards sustainability activities and further assists them to design and create working conditions / structures / QI planning / QI control practices, etc. Aim to craft towards sustainability pathway for desired QI outcomes. Even said the QI systems, initiatives/projects that implemented in the most hospital are useful tools and evidence-based practices for improving the patients' safety, quality care and services, but it could not guarantee the nurses to fully carry out for the sustainable QI outcomes, thus the healthcare management should well allocate the necessary fundamental supports/needs of job-related structures at workplace to keep pace with those QI system that could empowered the nurses to sustain reliable implementation and execution of safe, efficient, and effective care and would increase their work satisfaction and further fostering their participation and commitment of the nurses (Kanter,1993;Chandler,1986; Laschinger,2001;Torres,2017) towards sustainability activities through QI.

\section{Acknowledgments}

This work has been supported by Universiti Teknologi Malaysia. Gratitude would like to be expressed to Dr Beni Widarman Yus Kelana, for his immerse knowledge and guidance to me throughout the entire process. My utmost appreciation and thankful to Dr. Beni.

\section{References}

Abbasi, K. (2013). Sustainable Health Systems. (Ed.), World Economic Forum, Geneva, Switzerland.

Abdallah, A. (2014). Implementing quality initiatives in healthcare organizations: drivers and challenges, International Journal of Health Care Quality Assurance, 27 (3), pp. 166181.

Aiken, L. H., Sloane, D. M., Bruyneel, L., Van den Heede, K., Griffiths, P., Busse, R., Diomidous, M., Kinnunen, J., Kózka, M., Lesaffre, E., McHugh, M. D., Moreno-Casbas, M. T., Rafferty, A. M., Schwendimann, R., Scott, P. A., Tishelman, C., van Achterberg, T., Sermeus, W., \& RN4CAST consortium (2014). Nurse staffing and education and hospital mortality in nine European countries: a retrospective observational study. Lancet (London, England), 383(9931), 1824-1830. https://doi.org/10.1016/S0140- 
6736(13)62631-8

Andreasson, J., Eriksson, A., and Dellve, L. (2016). Health care managers 'views on and approaches toimplementing models for improving care processes', Journal of Nursing Management, Vol. 24No. 2, pp. 219-227

Chandler, G. (1986). The relationship of nursing work environment to empowerment and powerlessness, [Doctoral dissertation, University of Utah], ProQuest Dissertations and Thesis database.

https://collections.lib.utah.edu/dl_files/09/5c/095c3de8e3e533e69660380b5d7c938 08a7a77ad.pdf.

Doyle, C., Howe, C., Woodcock, T., Myron, R., Phekoo, K., McNicholas, C., Saffer, J., \& Bell, D. (2013). Making change last: applying the NHS institute for innovation and improvement sustainability model to healthcare improvement. Implementation science : IS, 8, 127. https://doi.org/10.1186/1748-5908-8-127

Ebrahimi, H., Hosseini, M. F., Amirnia, M., Mehraee, A., Jamali, V., Hejazi, S. A. (2012). Factors Influencing Nurses. Participation in Continuing Education Programs in Tabriz University of Medical Sciences, Iranian Journal of Medical Education, 12(7), pp. 518526.

Frich, J. C., Brewster, A. L., Cherlin, E. J., Bradley, E. H. (2015). Leadership development programs for physicians, J Gen Int Med, 30, pp. 656-74.

Hair, J. F. J., Hult, G. T. M., Ringle, C., \& Sarstedt, M. (2014). A Primer on Partial Least Squares Structural Equation Modeling (PLS-SEM). Long Range Planning (Vol. 46). https://doi.org/10.1016/j.Irp.2013.01.002

Homer, C. S. E., Friberg, I. K., Dias, M. A. B., Ten Hoope-Bender, P., Sandall, J., Speciale, A. M., \& Bartlett, L. A. (2014). The projected effect of scaling up midwifery. In The Lancet. https://doi.org/10.1016/S0140-6736(14)60790-X

Institute of Medicine. (2015). Measuring the Impact of Interprofessional Education on Collaborative Practice and Patient Outcomes, The National Academies Press, Washington, DC. https://doi.org/10.17226/21726.

Kanter, R. M. (1993). Men and women of the corporation (2nd ed.). Basic Books. A

Laschinger, H. K., Finegan, J., Shamian, J., \& Wilk, P. (2001). Impact of structural and psychological empowerment on job strain in nursing work settings: expanding Kanter's model. The Journal of nursing administration, 31(5), 260-272. https://doi.org/10.1097/00005110-200105000-00006

Lewis, S., \& McGowan, B. (2015). Newly qualified nurses, experiences of a preceptorship', British Journal of Nursing, 24(1), pp. 40-43. http://dx.doi.org/10.12968/bjon.2015.24.1.40.

Marshall, E. S. (2011). Transformational Leadership in Nursing: From expert Clinician to influential Leaders, New York, NY: Springer Publishing Company, LLC.

Martensson, G., Engstrom, M., Mamhidir, A.G., \& Kristofferzon, M.L. (2012). What are structural conditions of importance to preceptors' performance? Nurse Education Today, 33(5), pp. 444-449. doi: 10.1016/j.nedt.2012.04.015.

Member of The Perseus Books Group.

Morrell, D. L. (2011). Employee Perceptions and the Motivation of Nonmonetary Incentives, Compensation and Benefits Review, 43 (5), pp. 318-23.

Nilsen, P., Seing, I., Ericsson, C., Birken, S. A., \& Schildmeijer, K. (2020). Characteristics of successful changes in health care organizations: an interview study with physicians, registered nurses and assistant nurses. BMC health services research, 20(1), 147. 
https://doi.org/10.1186/s12913-020-4999-8

Porter-O'Grady T. (2001). Is shared governance still relevant? The Journal of Nursing Administration, 32, pp. 2-97.

Quality Improvement Division. (2018). Report of the review of the application of the Framework for Improving Quality in our Health services: Learning to guide future approaches. https://www.hse.ie/eng/about/who/qid/framework-for-qualityimprovement/executive-summary-review-of-the-framework-for improvingquality.pdf

Rajasekhar, P., Rees, C., Nixon, C., East, J., and Brown, S. (2016). Factors influencing change in clinical practice: a qualitative evaluation of the implementation of the $Q$ I in colonoscopy study, International Journal of Health Care Quality Assurance, 29 (1), pp. 5-15.

Reader, T. W. (2017). Team decision making In Salas R. R. E., \& Passmore J. (Eds.), The Wiley Blackwell handbook of the psychology of team working and collaborative processes, pp. 271-296, West Sussex, UK: Wiley Blackwell.

Torres, Y. M. (2017). Influence of Work Environment Conditions on the Ability of Critical Care Nurses to Provide Efficacious Nursing Care in Puerto Rico, [Doctoral Dissertations, University of Massachusetts Amherst], ScholarWorks@UMassAmhers.https://scholarworks.umass.edu/dissertations_2/113 2

Trede, F., Sutton, K., \& Bernoth, M. (2015). Conceptualizations and perceptions of the Nurse preceptor's role: A scoping review, Nurse Education Today, 36(2016), pp. 268-274. http://dx.doi.org/10.1016/j.nedt.2015.07.032.

Van Oostveen, C., \& Vermeulen, H. (2017). Greater nurse autonomy associated with lower mortality and failure to rescue rates. Evidence-based nursing, 20(2), 56. https://doi.org/10.1136/eb-2016-102591 